\title{
Aesthetic and Semiotic Approach to the Musical and Creative Development of Children with Antisocial Behavior Manifestations
}

\author{
Irina Cheremisova
}

Doctor of Psychological Sciences, Associate Professor, Head of the Department of Psychology at Volgograd State University; irinarusa@inbox.ru

\section{Doi:10.5901/mjss.2015.v6n6s5p351}

\section{Abstract}

\begin{abstract}
The article describes the psychological work aimed at musical and creative development of a group of preschool children with manifestations of antisocial behavior based on the principles and methods of aesthetic and semiotic approach which is new for the educational psychology. Musical art determines the creative development of the individual, greatly accelerates and optimizes this process. This is due to the specific features of the musical text, especially masterpieces as work of aesthetic and artistic value. As a result of the interaction of teachers, psychologists, parents in the conditions of a developing musical and creative environment, all children demonstrated significant and stable positive dynamics. Psychological support of musical and creative development of children with manifestations of antisocial behavior on the basis of aesthetic and semiotic approach helps to optimize their mental and personal development.
\end{abstract}

Keywords: musical-creative development, antisocial behavior, classical music, aesthetic and semiotic approach.

\section{Introduction}

The instability of the present political, social and economic situation in the country and in the world increases the level of tension in Russian society. This tension is associated with an increase of negative emotional and behavioral manifestations of individuals and different groups. In this situation there is an acute problem to prevent aggressive, conflict, anti-social behavior of citizens: both adults and children, teenagers and young people. It is especially important to carry out this work with children of preschool age who have a high level of sensitivity, emotionality, vulnerability, impressionability. Numerous studies have shown that the causes of antisocial behavior in children may be different. Directing the efforts on preventive and corrective work in this direction it is necessary to understand the basic reasons of the manifestations of anti-social behavior of children.

One of the reasons of violations of social adaptation of children is a pedagogical neglect. This concept means a deviation from the norm in child development due to deficiencies of education and training. Many parents do not know the age characteristics of children, the main pedagogical and psychological methods. Unfortunately, we have to admit that some teachers fail to use their professional knowledge, skills, lack of the necessary experience in dealing with children. This is particularly true of crisis age periods. Caution, patience and respectful attitude to the child, to his new requirements will let overcome these periods calmly and painlessly. Ignoring the interests of the child can lead to outbreaks of aggression, negativism, manifestations of anti-social behavior, uncontrollable behavior. As a result, the child may gain an unwanted pattern of behavior.

Some researchers point out that the social adaptation of children and adolescents is hampered by specific adverse individual features. These features are due to the presence of psychobiological preconditions of antisocial behavior of children and adolescents (Belicheva, 1994; Meneghetti, 1997 etc.). Various neurological diseases and psychiatric disorders (intracranial pressure, cerebral palsy, encephalopathy, epilepsy, minimal brain dysfunction, autism and others.) can impede learning social norms by a child and the formation of pro-social behaviors.

Mental retardation and oligophrenia are referred to psychobiological preconditions of antisocial behavior by the researches (Belicheva, 1994; Meneghetti, 1997 etc.)

Psycho-preventive and psycho-correction work with children with neurological disorders, mental disorders, various degrees of mental retardation should be carried out comprehensively with the participation of teachers, psychologists, doctors.

A powerful tool of educational influence, activation of cognitive and personal development is the musical art (Knyazeva, 2000; Kurisheva, 2008; Medvedeva, 2009; Shutova, 2008 etc.). The main factors of artistic influence of music 
on mental and personality development of the child, activation of creative potential are spiritual and moral content of music and emotional richness of masterpieces of classical music. In our concept, we use the term "diapason musical culture" which denotes the classical music art, pieces of music of academic genres classical composers (Kurisheva, 2008).

Theoretical analysis of scientific researches on the problems of creative development of an individual (Burton, et al., 2008; Feldman, et al., 1994; Gardner, 1988; Meneghetti, 1997; Rogers, 1961; Torrance, 1963), allowed us to determine the basic points of our study.

\section{Materials, Methods and Research Results}

The hypothesis of our study is the assumption that the aesthetic-semiotic approach to psychological and educational work with children of preschool age with the manifestations of anti-social behavior will ensure the effectiveness of musical influence.

On the basis of aesthetic and semiotic approach a musical-semantic model of the creative development of the personality was developed. This model became the basis for developing a program of psychological support, which has been tested with the work with children with manifestations of antisocial behavior. The experiment was conducted on the basis of in-patient neurological department of the children's clinic (12) and special school of type VIII (9 persons) of Nizhny Novgorod during the school year from September to May (for nine months).

As a control group there were children that were being treated in in-patient neurological department (10 persons) and pupils of the first class of a special school type VIII (10 persons).

Initial assessment was based on the method of observation. Using the diagnostic methods was not possible, as children did not take an instruction. The attention of children was distracted. Documentation of children was also studied, talks with parents, guardians and teachers were conducted. All the children had a backlog from the age norm, they had mental retardation. Children had insufficient knowledge about the surrounding world, narrowed active and passive vocabulary, mental operations were complicated, cognitive interest was underdeveloped. Children had an attention deficit, low working capacity, low learning disabilities, primitive gaming activities. They often demonstrated inadequate emotional and behavioral responses, impulsivity, hyperactivity, aggression.

The program of psychological support of musical and creative development of children was developed. The work with an experimental group was carried out in three ways: with the children, with their parents (guardians), with teachers.

Individual and group consultations with parents were conducted on the creating music and creative developing environment in the family. During the meetings they discussed the issues of age peculiarities of mental and personal development of children, the reasons and possible ways psycho-correction of manifestations of antisocial behavior of children. It should be noted that the work with the parents and guardians of our pupils has been very difficult. On the one hand, it was possible to conclude that they love children, but on the other hand, they often complained they have difficulty in communication and interaction with children. Adults did not understand why children were so intractable, they tried with help of punishment achieve positive results in training, development of social norms. Parents and guardians are also accused of incompetence and inaction of teachers, because they do not see quick positive results of their work. The near relations would withdraw from the process of training and education, shifting the work and care of the child, the responsibility for his health to teachers.

The following examples are very indicative:

Grandfather (guardian) of llya D. (6 years) was very tired of his grandson and to isolate him he was constantly was locking the child in the bathroom. Apparently, the boy spent in the room a lot of time, as his games and figures reflected images of objects of only sanitary ware, which he saw there.

Artem T. (5.5 years). The boy is hyperactive, aggressive, excitable, short-tempered. He often fights with peers and adults, shouts, curses. After the death of the mother he was taken to her old grandmother. Inadequate behavior of the boy, inappropriate emotional reactions, unexpected flashes of aggression led to the fact that she was beating him with slippers and driving him under the table. The child was there for a long time because of fear of punishment. Artem's guardian was his mother's sister, but after meeting with the boy, she refused the guardianship. The guardian became Artem's mother's stepsister. At the first meeting with the psychologist the woman angrily accused the child, expressed numerous grievances against him. The psychologist showed her the pictures which the boy made perceiving classical music, and explained that the boy was happily engaged in creative activities, spoke about the progress of the child. As a result of this conversation, the woman's face brightened, and she relented in the assessments of the child, in the attitude to him.

Methodological meetings and consultations were held in order to discuss the features of the development of their 
pupils, to optimize the interaction with parents and guardians.

The essence and content of psychological support in the musical-semiotic model determine the specific conditions, principles of making a musical creative developing environment, which is an essential component of musical-semiotic model presented in this study.

Realization of the program tasks of psychological support for children of preschool age with the manifestations of anti-social behavior aimed at musical and creative development of the child's personality by means of musical art, primarily presupposed the creation of conditions for spiritual communion with the art of music, more precisely classical music. Creating a project of such environment and technologies of cooperation of a child with adults and peers, pieces of music, initiation of children to the source of moral-aesthetic, spiritual development, revitalization of their creativity was one of the objectives of our study.

Creation of musical and creative developing environment in the educational process assumed taking into account peculiarities of children development in its structural, organizational and substantive components. The existence of the musical and creative environment in the educational process is stipulated by its variability, dynamism, expansion and selfdevelopment of environment as a result of interaction with the child that introduces changes to it. In turn, the environment created conditions for self-development of the child.

Organizing the process of development of a creative personality in the "musical-creative" environment, we relied on certain mechanisms.

The mechanism of the development of the creative personality in the musical and creative environment is based on a kind of artistic and aesthetic development of the values of the world music culture, the perception of classical music - as the best examples of manifestation of the spiritual life of an individual (a composer, performer) in the development of dialogic communication between a teacher and children in the process of perception the music. It has more to do with the factors that affect the process of musical perception; specificity of the artistic effects of musical art, aesthetic emotions, evaluations and activities aimed at creating artistic and creative products. Familiarizing children with cultural values was carried out through inter-subjective interaction in the art, in different shapes and forms of artistic activity, mastering signs and symbols of society and culture.

In this specific kind of familiarization children together with a teacher go along a path starting from the perception of beauty, contemplation, observation, study of mind and a sense of social and natural phenomena, reflected in the art, by perceiving aesthetic impressions and experiencing the development of different sensory standards (of sounds, rhythms, intonations, timbre, etc.), the properties of a musical sound, "musical language", through the reflection of impressions received in varying degrees of pleasure, joy and interest. The greatest impact has the "live" music. During the performance music is a wonderful meeting of three activities: a composer and a performer seek to express, to convey to the listener their ideas, thoughts and feelings; but the listener acts as the active side, he is also involved in the process of co-creation.

With the help of the teacher pupils learn (decode) the "musical language" and "language" of human emotions; comprehend the role of musical language in the context of culture, explore the features of musical language; they come to understand that speech and genres of music are based on some general communication laws. In the inter-subject dialogue in the art, in which the real world is reflected in the work of art, a child (as a listener, performer, composer), worrying, wondering, learning, reflecting on the relationship between people, natural phenomena, social events, acquires a personal meaning of the perceived. This process of reflection is due to age and psychological characteristics of the child, sensory experience, and technical skills. By means of operations, activities, facilities, signs and symbols of art, children, drawing on the support of the teacher learn to create their own way of seeing the world, to act as the creators of their ideas, images, as performers and composers. This ensures that the beginning of the birth of the preferential, selective, and then evaluating attitude that is the basis for the development of a creative personality and elaboration of the internal position of the attitude to the world, to oneself.

However, the development of the inner world of the child's personality, inculcating values is carried out not only in perception, but also in terms of active operations in various kinds of musical and creative activities (singing, tapping rhythm, improvisation, the performance of a musical work). Music has even more powerful educational influence in the process of musical creative work.

The mechanism of music therapy with the help of musical art ensures harmonization of the emotional states of children, correction of deviations in personal development in the process of the development of the creative personality in the educational space. It is manifested in the following points.

An opportunity by means of musical art in its distinctive symbolic form redesign traumatic for the child's situation and find a externally expressed way out of it.

Development of the ability to mobilize the experience of life at the right time, breeding strong-willed qualities, the 
ability to self-regulation. Children learn skills of their own selection of a piece of music for the self-regulation of their emotional states. Music provides unlimited opportunities for self-expression and self-actualization, empathy, co-creation in which there is an aesthetic response.

The ability to orientate educational work and pedagogical communication on goodwill, acceptance, trust, recognition of the uniqueness and diversity of each individual child's self-worth, the presence of the creative potential of each and the possibility of its development.

Possibility of relaxation of the psychological tone. Experimental studies (Knyazeva, 2000; Kurisheva, 2008; Shutova, 2008) show that classical music causes enlightenment and good feelings and the state contributes to the thinking and creative processes of the subjects.

Expansion and development of the emotional sphere, the development of aesthetic and spiritual needs. The emotions caused by art, are endowed with characteristics, one of its manifestation is the predominance of a positive core, due largely by having aesthetic pleasure. Emotions have certain mimic manifestations; on perceiving the works of art, they usually find a vivid expression and cannot be "delayed", which at the phenomena of reality are often dictated by the rules of ethics and everyday circumstances.

Creative products created by a child, objectifying its affective relationship to the world, help to facilitate the process of communication, establishing relationships with the significant others (parents, peers, other people). The adoption by the surrounding people the products of creativity contributes to a child's self-esteem, increase its degree of self-worth and self-value.

Perception of the best examples of world music is an affordable and efficient way of psychotherapeutic effects on humans. In studies of music therapy physiological mechanisms of the influence of musical art on the human psyche and his entire body were revealed (Kurisheva, 2008).

Connecting via music two mechanisms and technology (pedagogical and therapeutic) of the development of a creative personality and providing mental health in the single process of accompanying the development of the creative personality in the educational space, we have changed the traditional, differentiating approach between the teaching didactics and psychotherapy. Let's note the basic principles that are realized in our approach.

Most important is the principle of spirituality. This principle manifests itself in the direction of psychologicalpedagogical influence of the developing environment for the development of the spiritual realm; ensuring freedom, responsibility, meaningfulness, spiritual, moral and social values of each child.

The principle of humanity is expressed in the manifestation of unconditional love to the pupil, attention to him, and respect for his personality, positive attitude toward him, the development of his personality.

The principle of social conditionality of musical and creative environment that provides opportunities for development and meeting the needs of the subjects of the educational process in the love, respect, social support in the movement to his "I", in recognition on the part of the adult confirmation of values of each group member; the satisfaction of the whole complex of social-oriented, culturally-valued requirements.

The principle of correspondence of environment to needs and capabilities of each child enables to take into account in the organizational, methodological and substantive components revealed by diagnosis typical, individual difference between children, forms of their manifestation in communicative, emotional, creative relationships. A child in the space of the environment is able to feel like the owner of the surrounding world and its parts.

The principle of symbolism, metaphoricalness of awareness provides opportunities for semiotic development, the ability to see, to distinguish, to become aware of the symbolism of the world and culture. Artistic perception cannot be reduced to decoding and even processing information - rather it is refinement and processing. This principle has a great symbolic value for a person, as he has the opportunity to add an object to the environment that has a special symbolic value.

The principle of dialogism implements various dialogues: "language of arts"; the sphere of the external world (nature, human subjects), a pupil and the arts; a pupil or others; his dialogue with his "I".

The principle of rationality in the emotional intensity of musical and creative environment. However, the environment should not be emotionally overloaded, supersaturated, taking into consideration characteristics of the emotional sphere of the child, it should facilitate a child to acquire a positive emotional experience of interaction with the art of music and the arts with others, adequate reflection of his experiences and feelings.

The principle of a freedom of creative expression, providing independence of the child in determining his attitude to the environment: the ability to perceive, emulate, create, combine, explore; to choose the target, means, methods of action; to express one's views on events, actions.

The principle of integration, providing the interaction of secondary school (kindergarten, school) and musical educational institutions (Conservatory of Music, College of Music, a music school) and cultural institutions (Philharmonic 
Society, Opera and Ballet Theater, Musical Theater, Concert hall) to create musical and creative developing environment in which all subjects of the educational process can perceive the best examples of musical art. The purpose of this interaction is the maximum possible active involvement of children in the perception of musical masterpieces.

In the environment of a musical atmosphere a child is interacting with it. It was important for us to define the parameters of this interaction. In this regard, in our study we have identified the stage of development of the musical environment, forms of interaction of child with it, the results of the child's interaction with the environment in the development of musicality and creativity of the individual.

Functioning of a child in the musical environment includes several stages.

The first stage is immersion into musical and creative environment that is characterized by heterogeneity of flow (some show a degree of readiness, a motivation to act in such environment; others require training or maintenance assistance for inclusion into the environment and some subjects demonstrate a weakness of motivation and detachment). The position of a teacher, a psychologist, a parent is activation of interest and suggestion of co-creation, collaboration in music and creative activities without mandatory participation.

The second stage is the actual-operational (cooperation, familiarization with environment, "trial and error", correlation with one's experiences through music and creative, artistic activity). At this stage there are manifestations of the heterogeneity of assimilation of values and their expression in musical and creative art activities, all the difficulties of the value-oriented, communicative, reflexive, emotional and sensual nature, artistic and creative expressions that were identified in the diagnostic phase of the program. The position of teachers, psychologists, parents is active organizational and guiding, educational, emotional and supportive care, both in group and in individual classes, in leisure time.

The third stage is the regulatory and modeling (the ability of a pupil to mobilize the musical experience at the right time, the ability to self-regulation by means of music - the ability to make a choice of a piece of music for the selfregulation of emotional states, self-expression and self-actualization, empathy, co-creation). This stage is characterized by the close interrelation level of musicality and modeling capabilities of the creative process, managing it. The position of teachers, psychologists, parents in the process of interaction with a child in the conditions of environment was determined by the degree of his personal and professional maturity, creativity.

The second parameter is the child's interaction with the environment is the musical forms of interaction.

First of all, they are associated with different types of reproduction of a piece of music: "live music", recordings, and auditory presentation. Much attention was paid to the selection of works for the perception. All of them belonged to the "golden fund" of musical art; the level of the performers was also quite high.

We have developed a series of creative tasks using the potential of fine arts (sculpture, painting, drawing, art photography). In these tasks, children embody by means of fine arts images and moods that were evoked by the music. An important place in the program is given to psychotherapeutic exercise "Drawing the music", as well as the implementation of associative drawing on a particular topic in the process of perception.

The creative individuality of the child was developed in the course of sessions in speech, vocal, instrumental, rhythmic, plastic improvisation under the impression of listening to music (strumming a tune, clapping, tromping the rhythm, conducting, dancing).

The third parameter of interaction is the result of the interaction, which expresses the correlation of the child with the environment, the state of mental health, emotional comfort of the child after the implementation of the program, adequacy of self-expression of the child in his emotional, symbolic, communicative, reflective manifestations.

Having a successful result, overcoming difficulties, the child experienced joy and pleasure; he began to assess aesthetic merits of the objects of environment and his personal qualities, manifested in the relationship with the environment (other people, works of art). And in this case, the learned values that were perceived in art, moved into the personal values. A teacher and a psychologist at this stage of the child's interaction with the environment, creating a situation of "success", helped to strengthen and realize the positive results achieved in the movement to himself, his "l" through art.

Practical work with the use of the described methods and techniques involves the development of technology for building the musical creative developing environment in which these methods are embodied. Since the development of the creative personality in the musical environment is possible on condition of appropriateness and comprehension, we have identified components of environment in our research.

The first component is a spatially-subject, comprising: "music" space (the group of kindergarten, grades of school, a recreation, a concert hall, a theater), "cultural zone", where the child can function in musical art (listening, performing, composing music). As well as items that are enriched by the sensory experience of the child (watercolor paints, brushes, paper, pens, pencils, musical instruments, sound recordings, films, paintings, pictures, photo albums, books, postcards, etc.); posters; portraits of composers; photos of concerts, musical theater performances; exhibition of creative works of 
teachers and pupils, students and their parents.

The second component of the musical and creative developing environment is social and personal, ensuring the creation of the unity of emotional and spiritual space of the subjects (teachers and a preschool child, a child and his parents), the experience of positive communication that occurs in the interaction of an adult and a child with art.

This interaction is characterized by goodwill, positive attitude and cooperation of all the subjects of the educational process: a teacher, a psychologist and a preschool child; a preschooler with his peers; a preschool child, a child and his parents.

This interaction is aimed at stress relief, approval and cognition by the pupil his own "I", the creation of a situation of free expression. It helps to stimulate cognitive and motivational bases of the child's personality, communicative and reflexive processes, and emotional responsiveness in art.

This interaction requires the alignment of the content, the selection of appropriate technologies of musical environment (entertaining tasks, the best examples of classical music in a great performance).

In this case, both a teacher, and a psychologist, and parents act as repeaters of cultural values, provide emotional comfort of the child in the world of people and art, culture, and encourage him for creativity, self-realization and contribute to a qualitative change of the personality in the environment .

The third component is cultural and informative, providing a substantial part of the development of a creative personality of the child by means of music. It is represented by pieces of music; theater performances (opera, ballet, operetta), the programs of season performances and concerts; exhibition of creative works; musical versions of creative tasks; summaries of sessions aimed at the development of a creative personality, the assimilation of cultural and cognitive, moral and aesthetic values of humanistic culture.

\section{Discussion}

The dynamics of the psychomotor development of children was assessed on the basis on diagnostic techniques and levels designed by N.V. Shutova (2008). The analysis of the results of final psycho-diagnosis led to the conclusion of a stable positive dynamics of mental and personality development of the subjects of the experimental group. At the end of the school year, all children started to understand and accept verbal instructions, mastered the basic social norms, they began to control their behavior, perform the regime moments and learned a constructive dialogue and interaction with adults and peers. Inadequate emotional and behavioral reactions began to appear less often. Learning ability and performance of all the children of the experimental group improved significantly. The repertoire of emotions that children learn to express in a socially approved way expanded, they learned to understand the emotions of another person. Children of the experimental group demonstrated a more active cognitive interest, enriched image sphere, a motivation to study appeared. All teachers, parents and guardians have noted that as a result of participation in the program of psychological support of musical and creative development of children physical condition of children was improved: improved coordination increased the speed of reaction, flexibility and agility of movement. At the end of the school year, all children were able to do the task on the model, two thirds of them were able to perform a creative task. Children's activities enriched greatly. The children began to organize their own plot-role-playing games, assign roles, conform to it in the game. Children successfully mastered various musical games and games on the musical material. The psychological atmosphere in the children's group was improved. Children started to make friends. In the speech development of children it was also noted a significant improvement: active and passive vocabulary was expanded, the activity and initiative in communication was increased.

An important result of participation in the program was the change in the attitude of parents and guardians for their children, and teachers. Parents and guardians have become more attentive to the interests and needs of children, more tolerant of their weaknesses and failures, are more balanced in communication and interaction with children. Requirements for children started to be based on the actual mental state of the child. Most parents began to take an active role in the enrichment of musical and creative developing environment of educational institutions. They adopted and implemented the recommendations of a psychologist to create musical and creative developing environment at home. In general, the interaction of parents (guardians) with the teachers has been improved considerably, increased and strengthened the confidence in the staff of educational institutions. At the end of the school year it became possible that the children with the teachers or the parents visited the puppet theatre and opera, various concerts and exhibitions.

The children of control groups not participating in the program of psychological support on the basis of aesthetic and semiotic approach did not show any significant differences. 


\section{Conclusion}

The study showed the effectiveness of the program of psychological support of musical and creative development of preschool children with manifestations of anti-social behavior on the basis of positions of aesthetic and semiotic approach. The experiment proved that the involvement of children in different kinds of music and creative activities with the masterpieces of classical music contributes to the activation of psychomotor and personal development, optimization of the emotional tone of the child, harmonization of interpersonal relationships with peers and adults. An important result of the program is that participation in the program helped to optimize the interaction of all participants in the educational process: teachers, children and their parents, guardians.

\section{References}

Belicheva, S.A. (1994). Osnovy preventivnoj psihologii [Basics of Preventive Psychology]. Moskva: Redakcionno-izdatel'skij centr konsorciuma Social'noe zdorov'e Rossii.

Burton, J., Horowitz, R., Abeles, H. (2008). Leaning In and Through the Arts. New York: Columbia University.

Feldman, D. Y., Chikszentmihalyi, M., Gardner, H. (1994). Changing the world: A framework for the study of creativity. Yale: Yale Press.

Gardner, H. (1988). Creative lives and creative works: A synthetic scientific approach. In R. J. Sternberg (Eds.), The nature of creativity. New York: Cambridge University Press, 298-321.

Knyazeva, T.S. (2000). K voprosu 0 vozmozhnosti «ob"ektivnyh» izmerenij muzykal'nosti.( On the possibility of "objective" measurements of musicality) Zhurnal prikladnoj psihologii, 5, 3-5.

Medvedeva, E.A. (2009). Formirovanie lichnosti rebenka $s$ problemami psihicheskogo razvitiya sredstvami iskusstva $v$ artpedagogicheskom i artterapevticheskom prostranstve [Formation of the personality of the child with mental development problems by means of art in the artpedagogical and art-therapeutic environment]. Moskva: Institut konsul'tirovaniya i sistemnyh reshenii.

Kurisheva, I.V. (2008). Fundamental psychophysiology of music therapy of neurological diseases. International Journal of Psychophysiology, 69 (3), 302.

Menegetti, A. (1997). Klinicheskaya ontopsihologiya [Clinical Ontopsychology]. Moskva: Slavyanskaya associaciya Ontopsihologii.

Rogers, C.R. (1961). On Becoming a Person. Boston: Constable.

Shutova, N.V. (2008). Integrirovannoe psihicheskoe razvitie problemnyh detej sredstvami muzykal'nogo vozdejstviya [Integrated mental development of problem children by means of musical influences]. Nizhnij Novgorod: Nizhegorodskij gosudarstvennyj pedagogicheskij universitet.

Torrance, E.P. (1963). Education and Creative Potential. Minneapolis: Personnel press. 